\title{
Visit-to-visit blood pressure variability is a marker of cardiac diastolic function and carotid atherosclerosis
}

\author{
Rieko Okada ${ }^{1 *}$, Akira Okada ${ }^{2}$, Takashi Okada ${ }^{2}$, Mamoru Nanasato ${ }^{3}$ and Kenji Wakai ${ }^{1}$
}

\begin{abstract}
Background: The associations between visit-to-visit blood pressure (BP) variability and cardiac function and carotid atherosclerosis is not clear.

Methods: Study subjects were 144 subjects (80 were female, aged $73 \pm 9$ years) who underwent echocardiography and cervical ultrasonography. The ratio of early ventricular filling velocity to early diastolic mitral annular velocity (E/e'), ejection fraction, left ventricular mass index (LVMI), and maximum intima-media thickness (max-IMT) of the carotid artery were compared between the highest (high variability) and lowest (low variability) tertiles of the standard deviation of systolic BP $(9.9 \pm 3.5 \mathrm{mmHg})$.

Results: E/e' and max-IMT were significantly greater in the high variability group than in the low variability group after adjusting for age, sex, baseline systolic BP, and other covariates (high variability vs. low variability; E/e': $13.03 \pm$ 5.33 vs. $10.66 \pm 3.30$, multivariate-adjusted difference $(\beta)=1.82,95 \%$ confidence interval 0.06-3.58; max-IMT: $1.65 \pm$ $0.43 \mathrm{~mm}$ vs. $1.42 \pm 0.46 \mathrm{~mm}, \beta=0.20 \mathrm{~mm}, 95 \%$ confidence interval $0.03-0.36 \mathrm{~mm}$ ). There were no significant differences in LVMI or ejection fraction.

Conclusion: These results indicate that high visit-to-visit BP variability is associated with diastolic function and carotid atherosclerosis, and is a possible risk factor for diastolic dysfunction and atherosclerosis.
\end{abstract}

\section{Background}

Blood pressure (BP) variability is now considered to be an important risk factor for cardiovascular diseases (CVD) [1]. Visit-to-visit BP variability, which is assessed in several clinical visits and reflects long-term BP variability, was recently reported to be a strong predictor of CVD morbidity and mortality independently of BP level [2-4]. Carotid atherosclerosis, a marker for the risk of CVD [5], may also be associated with visit-to-visit BP variability [6]. However, there are limited data regarding the association between visit-to-visit BP variability and cardiac function measures [7]; thus, the mechanism underscoring the association between BP variability and CVD is unclear. Therefore, this study was conducted to investigate whether visit-to-visit BP variability is associated with measures of cardiac function and carotid

\footnotetext{
* Correspondence: rieokada@med.nagoya-u.ac.jp

${ }^{1}$ Department of Preventive Medicine, Nagoya University Graduate School of Medicine, 65 Tsurumai-cho, Showa-ku, Nagoya 466-8550, Japan

Full list of author information is available at the end of the article
}

atherosclerosis in subjects who underwent echocardiography and cervical ultrasonography at the same time.

\section{Methods}

\section{Study subjects}

This study was performed in 144 consecutive subjects (64 were male and 80 were female; mean age 73 years [SD, 9 years], range 35-93 years) who underwent echocardiography and cervical ultrasonography at the same time between September 2011 and August 2013 at Okada Medical Clinic in Nagoya, Japan. These data were collected during routine care and were extracted from medical charts, thus the patients for the examinations were not randomly collected for this study. The study subjects were; 15 with the history of coronary heart diseases, 10 with the history of stroke, 42 with diabetes, 118 with hypertension, and 46 with hyperlipidemia. Systolic and diastolic BP, heart rate, height, and weight at the time of echocardiography were used as baseline variables. Blood samples were also taken in the morning 
after an 8-h overnight fast to measure laboratory variables. Fasting plasma glucose, hemoglobin A1c, and serum lowdensity lipoprotein cholesterol, uric acid and creatinine were measured using standard laboratory techniques, and the estimated glomerular filtration rate was calculated as previously described [8]. We also recorded whether the subjects used calcium-channel blockers, angiotensin receptor blockers, $\beta$-blockers, glucose-lowering drugs, or lipid-lowering drugs. Three subjects were taking low-dose diuretics for their symptom of heart failure. Histories of CVD (coronary heart diseases or stroke) were also recorded. Subjects with atrial fibrillation or valvular diseases were excluded from the study. The study was approved by the ethics committee of Nagoya University Graduate School of Medicine (approval number 2013-0182) and the ethics committee of Nagoya Medical Association.

\section{$\mathrm{BP}$ measurement and BP variability}

We retrospectively reviewed the subjects' medical records to retrieve $\mathrm{BP}$ values recorded over 1 year before the echocardiographic examination. BP was measured in an outpatient clinic every 1 to 3 months using the conventional cuff method using the standard protocol of BP measurement by the Japanese Society of Cardiovascular Disease Prevention. BP variability was retrospectively assessed. The standard deviation (SD) of systolic BP from 4 to $13 \mathrm{BP}$ measurements was used as an index of BP variability, as reported in earlier studies $[2,3,6,9-11]$. Subjects were classified into tertiles of the SD of systolic BP as used in the previous study [2], because the number of study subjects was not enough to use quartile [9] or decile [3] as used in the other studies. The lowest tertile was classified as low variability, the middle tertile as middle variability, and the highest tertile as high variability.

\section{Echocardiographic examination}

Echocardiographic examinations were performed by a single sonographer who assessed cardiac structural changes and cardiac function. Two-dimensional (2D) echocardiography and M-mode echocardiography were performed using high-resolution ultrasound (Apron EUB-7000HV; Hitachi Medical Corporation, Tokyo, Japan). Left ventricular (LV) diastolic function was assessed by transmittal pulse-wave Doppler to measure mitral inflow early $(\mathrm{E})$ and late (A) diastolic filling velocities, E/A ratio, and tissue Doppler imaging parameters, including the early diastolic mitral annular velocity (e'), which was measured on the lateral side of mitral annulus. The E/e' ratio was measured as an index of LV filling pressure. Diastolic dysfunction was defined as E/e' $\geq 15$ [12]. The left atrial dimension was measured on 2D-guided M-mode echocardiographic images of the base of the heart obtained in the parasternal short-axis view. Ejection fraction was measured using a quantitative 2D method (biplane Simpson method of disks) [13]. The LV mass index (LVMI) was calculated using Devereux's equation and was adjusted for body surface area [14].

Arterial stiffness was assessed by measuring the carotid intima-media thickness (IMT) just after echocardiography by high-resolution ultrasound, as described above, with a 7.5-MHz linear array transducer. The maximum IMT (max-IMT) was defined as the single thickest wall of the near and far right or left walls of the common carotid artery, bulbus, and internal carotid artery, including plaques, as a marker of carotid atherosclerosis [5]. The lesion was scanned bilaterally in longitudinal and transverse projections. The max-IMT was measured at the site of the most advanced atherosclerotic lesion that exhibited the greatest distance between the lumenintimal interface and the media-adventitia interface. Carotid atherosclerosis was defined as a focal wall thickness of $>1.5 \mathrm{~mm}$ [15].

\section{Statistical analyses}

Clinical, echocardiography, and cervical ultrasonography variables were compared among the tertile groups of BP variability using analysis of variance for continuous variables or $\mathrm{X}^{2}$ tests for dichotomous variables. Variables that showed statistically significant differences among the three groups were then included in multivariate analyses. $\beta$ coefficients (the differences between the highest or middle tertile and the lowest tertile) and $95 \%$ confidence intervals $(\mathrm{CI})$ were calculated for each variable by linear regression with adjustment for age (continuous), sex, baseline systolic BP (continuous), use of antihypertensive drugs, and history of CVD. Odds ratios and 95\% CIs were calculated for the prevalence of diastolic dysfunction and carotid atherosclerosis by unconditional logistic regression with adjustment for the same covariates. Values of $\mathrm{P}<0.05$ in adjusted models were considered statistically significant. All analyses were performed using STATA software version 9 (Stata Corp, College Station, TX, USA).

\section{Results}

BP was measured for $9.5 \pm 2.9$ times during one year (range 4 to 13 times), and mean systolic BP was $130 \pm$ $10 \mathrm{mmHg}$; the lowest tertile (SD $<8.29 \mathrm{mmHg}$ ), the middle tertile (SD 8.29-10.99 $\mathrm{mmHg}$ ), and the highest tertile (SD $>10.99 \mathrm{mmHg}$ ). The clinical, echocardiography, and cervical ultrasonography variables for the study subjects are summarized by BP variability level in Tables 1 and 2 . The high BP variability group tended to be older, had a higher proportion of female subjects, and had higher lipid levels compared with the other groups of subjects, although the differences in these are not statistically significant. The mean ejection fraction was 57\%; two-thirds 
Table 1 Characteristics of subjects according to the level of blood pressure variability $(n=144)$

\begin{tabular}{|c|c|c|c|c|}
\hline & \multicolumn{4}{|c|}{ Blood pressure variability } \\
\hline & Low variability & Middle variability & High variability & $P$ value \\
\hline$n$ & 48 & 48 & 48 & \\
\hline Age (years) & $72.3 \pm 9.1$ & $70.8 \pm 8.5$ & $74.7 \pm 8.7$ & $0.101^{\mathrm{a}}$ \\
\hline Male & $24(50.0 \%)$ & $21(43.8 \%)$ & $19(39.6 \%)$ & $0.586^{\mathrm{b}}$ \\
\hline Blood pressure measurements (times) & $9.1 \pm 3.1$ & $9.5 \pm 2.6$ & $9.7 \pm 2.8$ & $0.569^{\mathrm{a}}$ \\
\hline Systolic blood pressure $(\mathrm{mmHg})$ & $130.2 \pm 10.1$ & $132.0 \pm 12.2$ & $131.5 \pm 16.9$ & $0.801^{a}$ \\
\hline Diastolic blood pressure (mmHg) & $72.1 \pm 11.0$ & $72.8 \pm 11.8$ & $71.2 \pm 10.3$ & $0.780^{\mathrm{a}}$ \\
\hline Pulse pressure $(\mathrm{mmHg})$ & $58.1 \pm 12.3$ & $59.2 \pm 11.5$ & $60.3 \pm 15.4$ & $0.728^{a}$ \\
\hline Heart rate (beats/min) & $73.8 \pm 9.8$ & $70.5 \pm 6.8$ & $72.3 \pm 6.9$ & $0.248^{\mathrm{a}}$ \\
\hline Antihypertensive medication & $33(68.8 \%)$ & $38(79.2 \%)$ & $41(85.4 \%)$ & $0.140^{b}$ \\
\hline Calcium-channel blocker & $27(56.3 \%)$ & $30(62.5 \%)$ & $34(70.8 \%)$ & $0.331^{b}$ \\
\hline Renin-angiotensin antagonist & $20(41.7 \%)$ & $19(39.6 \%)$ & $24(50.0 \%)$ & $0.553^{\mathrm{b}}$ \\
\hline$\beta$-blocker & $6(12.5 \%)$ & $9(18.8 \%)$ & $3(6.3 \%)$ & $0.180^{b}$ \\
\hline Fasting plasma glucose (mg/dL) & $116.3 \pm 41.5$ & $118.8 \pm 47.8$ & $115.5 \pm 38.9$ & $0.923^{\mathrm{a}}$ \\
\hline HbA1c (\%) & $6.12 \pm 0.94$ & $5.98 \pm 0.80$ & $5.82 \pm 0.60$ & $0.173^{\mathrm{a}}$ \\
\hline Glucose-lowering medication & $8(16.7 \%)$ & $8(16.7 \%)$ & $8(16.7 \%)$ & $1.000^{b}$ \\
\hline LDL-cholesterol (mg/dl) & $114.2 \pm 24.0$ & $118.0 \pm 28.2$ & $124.6 \pm 25.5$ & $0.146^{\mathrm{a}}$ \\
\hline Lipid-lowering medication & $13(27.1 \%)$ & $16(33.3 \%)$ & $17(35.4 \%)$ & $0.660^{b}$ \\
\hline Uric acid (mg/dL) & $5.50 \pm 1.26$ & $5.25 \pm 1.29$ & $5.38 \pm 1.32$ & $0.643^{\mathrm{a}}$ \\
\hline Body mass index $\left(\mathrm{kg} / \mathrm{m}^{2}\right)$ & $24.13 \pm 3.87$ & $24.03 \pm 3.20$ & $24.19 \pm 3.56$ & $0.977^{\mathrm{a}}$ \\
\hline eGFR $\left(\mathrm{ml} / \mathrm{min} / 1.73 \mathrm{~m}^{2}\right)$ & $68.0 \pm 19.4$ & $67.5 \pm 15.9$ & $64.9 \pm 17.8$ & $0.667^{a}$ \\
\hline Proteinuria & $4(8.3 \%)$ & $6(12.5 \%)$ & $7(14.6 \%)$ & $0.627^{b}$ \\
\hline Cardiovascular disease & $9(18.8 \%)$ & $8(16.7 \%)$ & $7(14.6 \%)$ & $0.861^{b}$ \\
\hline
\end{tabular}

Data are means \pm standard deviation or $\mathrm{n}(\%)$. Low, middle, and high variability are defined as the lowest $(<8.29 \mathrm{mmHg})$, middle $(8.29-10.99 \mathrm{mmHg})$, and highest $(>10.99 \mathrm{mmHg}$ ) tertiles of the standard deviation of systolic blood pressure, respectively.

LDL-cholesterol, low-density lipoprotein cholesterol; eGFR, estimated glomerular filtration rate.

${ }^{a}$ Analysis of covariance; ${ }^{b} x^{2}$ test.

Table 2 Echocardiography, and cervical ultrasonography characteristics of subjects according to the level of blood pressure variability $(n=144)$

\begin{tabular}{lllll}
\hline & \multicolumn{2}{l}{ Blood pressure variability } & & \\
\cline { 2 - 5 } & Low variability & Middle variability & High variability & P value $^{\mathbf{a}}$ \\
\hline $\mathrm{n}$ & 48 & 48 & 48 & \\
Left atrium diameter $(\mathrm{mm})$ & $37.3 \pm 5.0$ & $36.4 \pm 4.6$ & $37.6 \pm 6.2$ & 0.541 \\
$\mathrm{E}(\mathrm{m} / \mathrm{s})$ & $0.53 \pm 0.13$ & $0.59 \pm 0.19$ & $0.57 \pm 0.20$ & 0.162 \\
$\mathrm{~A}(\mathrm{~m} / \mathrm{s})$ & $0.71 \pm 0.15$ & $0.77 \pm 0.17$ & $0.77 \pm 0.19$ & 0.153 \\
$\mathrm{e}^{\prime}(\mathrm{m} / \mathrm{s})$ & $0.054 \pm 0.019$ & $0.053 \pm 0.012$ & $0.048 \pm 0.019$ & 0.189 \\
E/A & $0.77 \pm 0.26$ & $0.80 \pm 0.29$ & $0.76 \pm 0.29$ & 0.845 \\
E/e' & $10.66 \pm 3.30$ & $11.60 \pm 3.36$ & $13.03 \pm 5.33$ & 0.019 \\
LVMI (mm) & $139.0 \pm 27.3$ & $137.0 \pm 23.6$ & $148.1 \pm 30.7$ & 0.108 \\
Ejection fraction (\%) & $58.3 \pm 9.1$ & $58.2 \pm 6.8$ & $57.5 \pm 8.1$ & 0.859 \\
Max-IMT (mm) & $1.42 \pm 0.46$ & $1.36 \pm 0.37$ & $1.65 \pm 0.43$ & 0.003 \\
\hline
\end{tabular}

Data are means \pm standard deviation or $\mathrm{n}(\%)$. Low, middle, and high variability are defined as the lowest $(<8.29 \mathrm{mmHg}), \mathrm{middle}(8.29-10.99 \mathrm{mmHg})$, and highest $(>10.99 \mathrm{mmHg}$ ) tertiles of the standard deviation of systolic blood pressure, respectively.

E, early ventricular filling velocity; A, late ventricular filling velocity; e', early diastolic mitral annular velocity; LVMI, left ventricular mass index; max-IMT, maximum intima-media thickness.

${ }^{\mathrm{a}}$ Analysis of covariance. 
of the subjects had normal systolic function (ejection fraction $\geq 55 \%$ ). The LVMI was greatest in the high BP variability group, although this difference was not statistically significant. There were no differences in ejection fraction among the three groups.

Because E/e' and max-IMT were significantly different between the $\mathrm{BP}$ variability groups $(\mathrm{P}<0.05$ by Tukey method), multivariate analyses were performed to examine the associations between BP variability and $\mathrm{E} / \mathrm{e}^{\prime}$ and max-IMT. Both E/e' and max-IMT were significantly greater in the high $\mathrm{BP}$ variability group than in the low $\mathrm{BP}$ variability group also in the multivariate models (high BP variability, middle BP variability vs. low BP variability; E/e': $13.03 \pm 5.33,11.60 \pm 3.36$ vs. $10.66 \pm 3.30$, multivariate-adjusted difference $(\beta)=1.82$, 95\% CI $0.06-$ 3.58 for high BP variability and $\beta=0.92$, $95 \% \mathrm{CI}-0.44-$ 2.29 for middle BP variability; max-IMT $1.65 \pm 0.43 \mathrm{~mm}$, $1.36 \pm 0.37 \mathrm{~mm}$ vs. $1.42 \pm 0.46 \mathrm{~mm}, \beta=0.20 \mathrm{~mm}, 95 \% \mathrm{CI}$ $0.03-0.36 \mathrm{~mm}$ for high BP variability and $\beta=-0.02 \mathrm{~mm}$, 95\% CI $-0.17-0.13 \mathrm{~mm}$ for middle BP variability).

Additionally, the prevalence rates of diastolic dysfunction and carotid atherosclerosis were greater in the high BP variability group than in the low $\mathrm{BP}$ variability group. The risk of carotid atherosclerosis was significantly greater in the high BP variability group compared with the low variability group (69\% vs. $38 \%$, OR 4.93, 95\% CI 1.75-13.91) in the multivariate model. Also, the risk of diastolic dysfunction was greater in the high BP variability group compared with the low variability group although it was not statistically significant after adjustment (29\% vs. $10 \%$; OR 2.71 , 95\% CI 0.78-9.38) (Table 3).

\section{Discussion}

To the best of our knowledge, this was the first study to reveal that greater visit-to-visit BP variability is significantly associated with both decreased diastolic function and carotid atherosclerosis independently of mean BP. These findings may provide new insights into the mechanism underlying the relationship between visit-tovisit $B P$ variability and CVD.

Recent data suggest that BP variability is a strong prognostic factor for stroke, coronary heart disease, and all-cause mortality [1-4]. There are several methods to measure BP variability; visit-to-visit BP variability represents long-term BP variability while 24-h BP variability assessed by ambulatory blood pressure monitoring represents short-term BP variability. Prior studies showed that greater visit-to-visit BP variability was independently associated with increased risk of coronary heart disease [4], stroke [3], and all-cause mortality [2]. Visitto-visit BP variability may be a predictor of CVD compared with mean BP [3] or 24-h BP variability [16]. Thus, visit-to-visit BP variability is a useful and easily measurable marker of CVD.

This study showed that visit-to-visit BP variability was associated with carotid IMT. Carotid IMT is a wellestablished marker of subclinical atherosclerosis, and it is strongly associated with the risk of future CVD events including coronary heart disease and stroke [5]. Recent studies have demonstrated that visit-to-visit BP variability is also associated with aortic distensibility [9] and endothelial dysfunction [10], which are also markers of subclinical atherosclerosis $[17,18]$. Higher $24-\mathrm{h}$ BP variability was reported to be a strong predictor of IMT increase [19], and one study demonstrated an association between higher visit-to-visit BP variability and greater IMT [6]. Fluctuations in BP cause a vascular damage [11]. Steep BP variations increase the oscillatory shear stress in the vessel wall of medium and large arteries. This enhances the traumatic effect of intravascular pressures on the vessel wall that ultimately results in the progression of atherosclerosis [20,21]. Meanwhile impairments in baroreflex sensitivity caused by structural changes of blood vessels increases BP variability [22]. These mechanisms may explain the relationship between $\mathrm{BP}$ variability and IMT.

Table 3 Prevalence of diastolic dysfunction and carotid atherosclerosis according to the level of blood pressure variabilit

\begin{tabular}{|c|c|c|c|c|c|c|c|c|}
\hline & \multicolumn{8}{|c|}{ Blood pressure variability } \\
\hline & \multicolumn{2}{|c|}{ Low variability } & \multicolumn{3}{|c|}{ Middle variability } & \multicolumn{3}{|c|}{ High variability } \\
\hline & n (\%) & OR & n (\%) & $\begin{array}{l}\text { Crude OR } \\
(95 \% \mathrm{Cl})\end{array}$ & $\begin{array}{l}\text { Adjusted OR } \\
(95 \% \mathrm{Cl})^{\mathrm{a}}\end{array}$ & n (\%) & $\begin{array}{l}\text { Crude OR } \\
(95 \% \mathrm{Cl})\end{array}$ & $\begin{array}{l}\text { Adjusted OR } \\
(95 \% \mathrm{Cl})^{\mathrm{a}}\end{array}$ \\
\hline \multicolumn{9}{|l|}{ Diastolic dysfunction } \\
\hline$E / e^{\prime}<15$ & 43 (89.6) & & $41(85.4)$ & & & $34(70.8)$ & & \\
\hline$E / e^{\prime} \geq 15$ & $5(10.4)$ & 1 (reference) & $7(14.6)$ & $1.47(0.43-5.00)$ & $1.33(0.36-4.92)$ & $14(29.2)$ & $3.54(1.16-10.81)$ & $2.71(0.78-9.38)$ \\
\hline \multicolumn{9}{|l|}{ Carotid atherosclerosis } \\
\hline Max-IMT $\leq 1.5 \mathrm{~mm}$ & $30(62.5)$ & & $29(60.4)$ & & & $15(31.2)$ & & \\
\hline Max-IMT >1.5 mm & $18(37.5)$ & 1 (reference) & 19 (39.6) & $1.09(0.48-2.48)$ & $1.47(0.53-4.08)$ & $33(68.8)$ & $3.67(1.58-8.54)$ & $4.93(1.75-13.91$ \\
\hline
\end{tabular}

$\mathrm{OR}$, odds ratio; $\mathrm{Cl}$, confidence interval; E/e', early ventricular filling velocity/early diastolic mitral annular velocity; IMT, intima-media thickness.

${ }^{a}$ Adjusted for age, sex, baseline systolic blood pressure, use of antihypertensive drugs, and history of cardiovascular disease. 
Diastolic dysfunction is believed to be the main cause of heart failure with preserved ejection fraction [23]. Previous studies revealed that diastolic dysfunction was a predictor of CVD mortality [24], and had a prognostic significance similar to systolic dysfunction [25]. Little is known about the association between BP variability and diastolic function. To our knowledge, only one study of 40 hypertensive patients has revealed an association between visit-to-visit BP variability and diastolic function [8]. This relationship might be mediated by impaired baroreflex sensitivity. Impaired baroreflex sensitivity caused by sinoaortic denervation resulted in an increase in BP variability and diastolic dysfunction in an animal model $[26,27]$, which suggests that sympathetic modulation of BP can cause diastolic dysfunction. Another mechanism might involve the association between arterial stiffening and diastolic dysfunction (that is, arterialventricular coupling) [28,29], which was reported to cause heart failure with preserved ejection fraction $[30,31]$. Because cardiac relaxation is delayed if cardiac afterload is increased by arterial stiffening [28], some studies have shown that greater carotid IMT is associated with diastolic dysfunction [32,33].

The LVMI was greater in subjects with higher BP variability, which was consistent with the former study [34], although it was not statistically significant. And systolic function was not associated with BP variability. Diastolic dysfunction precedes LV hypertrophy in the development of hypertension [35], and diastolic dysfunction precedes systolic dysfunction in the process subclinical atherosclerosis [33]. Thus, the association between BP variability and diastolic function may precede the development of LV hypertrophy and systolic dysfunction.

Several limitations of this study should be mentioned. First, because of the relatively small number of subjects, we could not perform analyses after stratifying the subjects according to their age or the presence of hypertension. Most of the prior studies that showed associations between BP variability and diastolic function or IMT were performed in elderly subjects with hypertension $[6,7]$, and the effects of BP variability might be differ between age groups or sexes [36]. Further studies are needed to examine whether the associations between BP variability and diastolic function or IMT are also apparent in middle-aged subjects or non-hypertensive subjects. Also, the study with a larger sample size is required to confirm the result of the multivariable adjustments. The strength of the association became weaker for diastolic dysfunction and stronger for carotid atherosclerosis after adjustment, which should be considered in the future studies. Second, the number of visits to assess BP variability was rather small, the number of visits was not the same for all the subjects in this study, and the interval between visits were not the same, which influence BP variability [37]. The study with a larger number of visits and the same number of visits for all the subjects is needed for the better assessment of $\mathrm{BP}$ variability, especially in the study with small number of subjects. Third, these data were collected during routine care and were extracted from medical charts, thus the patients for the examinations were not randomly collected for this study, which may affect the study results. Fourth, considering the cross-sectional design of this study, we could not determine whether treating patients with high BP variability can prevent the progression to diastolic dysfunction and carotid atherosclerosis. This possibility should be examined in longitudinal studies.

\section{Conclusions}

Visit-to-visit BP variability recorded over 1 year was associated with cardiac diastolic function and carotid atherosclerosis. In addition to other well-defined risk factors, we suggest that visit-to-visit BP variability is considered as a marker for the development of diastolic dysfunction and atherosclerosis. Measurements of cardiac function and carotid atherosclerosis may be warranted in subjects with high BP variability.

\section{Competing interests}

The authors declare that they have no competing interests.

\section{Author's contributions}

$\mathrm{RO}$ analyzed data and mainly drafted the article, $\mathrm{AO}, \mathrm{TO}, \mathrm{MN}$, and $\mathrm{KW}$ provided intellectual content of critical importance to the work described and revised the article, and all the authors approved the final version of the article to be published.

\section{Author details}

${ }^{1}$ Department of Preventive Medicine, Nagoya University Graduate School of Medicine, 65 Tsurumai-cho, Showa-ku, Nagoya 466-8550, Japan. ${ }^{2}$ Okada Medical Clinic, Nagoya, Japan. ${ }^{3}$ Cardiovascular Center, Nagoya Daini Red Cross Hospital, Nagoya, Japan.

Received: 26 September 2014 Accepted: 11 December 2014 Published: 15 December 2014

\section{References}

1. Diaz KM, Tanner RM, Falzon L, Levitan EB, Reynolds K, Shimbo D, Muntner P: Visit-to-visit variability of blood pressure and cardiovascular disease and all-cause mortality: a systematic review and meta-analysis. Hypertension 2014, 64:965-982.

2. Muntner P, Shimbo D, Tonelli M, Reynolds K, Arnett DK, Oparil S: The relationship between visit-to-visit variability in systolic blood pressure and all-cause mortality in the general population: findings from NHANES III, 1988 to 1994. Hypertension 2011, 57:160-166.

3. Rothwell PM, Howard SC, Dolan E, O'Brien E, Dobson JE, Dahlöf B, Sever PS, Poulter NR: Prognostic significance of visit-to-visit variability, maximum systolic blood pressure, and episodic hypertension. Lancet 2010, 375:895-905.

4. Mancia G: Prognostic value of long-term blood pressure variability: the evidence is growing. Hypertension 2011, 57:141-143.

5. Polak JF, Szklo M, Kronmal RA, Burke GL, Shea S, Zavodni AE, O'Leary DH: The value of carotid artery plaque and intima-media thickness for incident cardiovascular disease: the multi-ethnic study of atherosclerosis. J Am Heart Assoc 2013, 2:e000087.

6. Nagai M, Hoshide S, Ishikawa J, Shimada K, Kario K: Visit-to-visit blood pressure variations: new independent determinants for carotid artery 
measures in the elderly at high risk of cardiovascular disease. J Am SoC Hypertens 2011, 5:184-192.

7. Masugata H, Senda S, Murao K, Inukai M, Hosomi N, Iwado Y, Noma T, Kohno M, Himoto T, Goda F: Visit-to-visit variability in blood pressure over a 1-year period is a marker of left ventricular diastolic dysfunction in treated hypertensive patients. Hypertens Res 2011, 34:846-850.

8. Matsuo S, Imai E, Horio M, Yasuda Y, Tomita K, Nitta K, Yamagata K, Tomino Y, Yokoyama H, Hishida A, Collaborators developing the Japanese equation for estimated GFR: Revised equations for estimated GFR from serum creatinine in Japan. Am J Kidney Dis 2009, 53:982-992.

9. Shimbo D, Shea S, McClelland RL, Viera AJ, Mann D, Newman J, Lima J, Polak JF, Psaty BM, Muntner P: Associations of aortic distensibility and arterial elasticity with long-term visit-to-visit blood pressure variability: the Multi-Ethnic Study of Atherosclerosis (MESA). Am J Hypertens 2013, 26:896-902.

10. Diaz KM, Veerabhadrappa P, Kashem MA, Feairheller DL, Sturgeon KM, Williamson ST, Crabbe DL, Brown MD: Relationship of visit-to-visit and ambulatory blood pressure variability to vascular function in African Americans. Hypertens Res 2012, 35:55-61.

11. Lattanzi S, Luzzi S, Provinciali L, Silvestrini M: Blood pressure variability predicts cognitive decline in Alzheimer's disease patients. Neurobiol Aging 2014, 35:2282-2287.

12. Nagueh SF, Bierig SM, Budoff MJ, Desai M, Dilsizian V, Eidem B, Goldstein SA, Hung J, Maron MS, Ommen SR, Woo A, American Society of Echocardiography, American Society of Nuclear Cardiology, Society for Cardiovascular Magnetic Resonance, Society of Cardiovascular Computed Tomography: American society of echocardiography clinical recommendations for multimodality cardiovascular imaging of patients with hypertrophic cardiomyopathy: endorsed by the American society of nuclear cardiology, society for cardiovascular magnetic resonance, and society of cardiovascular computed tomography. J Am Soc Echocardiogr 2011, 24:473-498.

13. Lang RM, Bierig M, Devereux RB, Flachskampf FA, Foster E, Pellikka PA, Picard MH, Roman MJ, Seward J, Shanewise J, Solomon S, Spencer KT, St John Sutton M, Stewart W, American Society of Echocardiography's Nomenclature and Standards Committee, Task Force on Chamber Quantification, American College of Cardiology Echocardiography Committee, American Heart Association, European Association of Echocardiography, European Society of Cardiology: Recommendations for chamber quantification. Eur J Echocardiogr 2006, 7:79-108.

14. Devereux RB, Alonso DR, Lutas EM, Gottlieb GJ, Campo E, Sachs I, Reichek N: Echocardiographic assessment of left ventricular hypertrophy: comparison to necropsy findings. Am J Cardiol 1986, 57:450-458.

15. Polak JF, Pencina MJ, Pencina KM, O'Donnell CJ, Wolf PA, D'Agostino RB Sr: Carotid-wall intima-media thickness and cardiovascular events. N Engl J Med 2011, 365:213-221.

16. Eguchi K, Hoshide S, Schwartz JE, Shimada K, Kario K: Visit-to-visit and ambulatory blood pressure variability as predictors of incident cardiovascular events in patients with hypertension. Am J Hypertens 2012, 25:962-968.

17. Elbasan Z, Sahin DY, Gür M, Kalkan GY, Yıldız A, Kaya Z, Kıvrak A, Gözübüyük G Özdoğru I, Çaylı M: Aortic distensibility and aortic intima-media thickness in patients without clinical manifestation of atherosclerotic cardiovascular disease. Echocardiography 2013, 30:407-413.

18. Campuzano R, Moya JL, García-Lledó A, Tomas JP, Ruiz S, Megías A, Balaguer J, Asín E: Endothelial dysfunction, intima-media thickness and coronary reserve in relation to risk factors and Framingham score in patients without clinical atherosclerosis. J Hypertens 2006, 24:1581-1588.

19. Sander D, Kukla C, Klingelhöfer J, Winbeck K, Conrad B: Relationship between circadian blood pressure patterns and progression of early carotid artery stenosis: a 3-year follow-up study. Circulation 2000, 102:1536-1541.

20. Manios E, Stamatelopoulos K, Tsivgoulis G, Barlas G, Koroboki E, Tsagalis G, Michas F, Vemmos K, Zakopoulos N: Time rate of blood pressure variation: a new factor associated with coronary atherosclerosis. J Hypertens 2011, 29:1109-1114

21. Chappell DC, Varner SE, Nerem RM, Medford RM, Alexander RW: Oscillatory shear stress stimulates adhesion molecule expression in cultured human endothelium. Circ Res 1998, 82:532-539.

22. Omboni S, Parati G, Di Rienzo M, Wieling W, Mancia G: Blood pressure and heart rate variability in autonomic disorders: a critical review. Clin Auton Res 1996, 6:171-182.
23. Schillaci G, Pasqualini L, Verdecchia P, Vaudo G, Marchesi S, Porcellati C, de Simone G, Mannarino E: Prognostic significance of left ventricular diastolic dysfunction in essential hypertension. J Am Coll Cardiol 2002, 39:2005-2011.

24. Zile MR, Brutsaert DL: New concepts in diastolic dysfunction and diastolic heart failure: Part I: diagnosis, prognosis, and measurements of diastolic function. Circulation 2002, 105:1387-1393.

25. Owan TE, Hodge DO, Herges RM, Jacobsen SJ, Roger VL, Redfield MM: Trends in prevalence and outcome of heart failure with preserved ejection fraction. N Engl J Med 2006, 355:251-259.

26. Flues K, Moraes-Silva IC, Mostarda C, Souza PR, Diniz GP, Moreira ED, Piratello AC, Chaves ML, De Angelis K, Salemi VM, Irigoyen MC, Caldini EG: Cardiac and pulmonary arterial remodeling after sinoaortic denervation in normotensive rats. Auton Neurosci 2012, 166:47-53.

27. Mostarda C, Moraes-Silva IC, Moreira ED, Medeiros A, Piratello AC, ConsolimColombo FM, Caldini EG, Brum PC, Krieger EM, Irigoyen MC: Baroreflex sensitivity impairment is associated with cardiac diastolic dysfunction in rats. $J$ Card Fail 2011, 17:519-525

28. Kass DA: Ventricular arterial stiffening: integrating the pathophysiology. Hypertension 2005, 46:185-193.

29. Chantler PD, Lakatta EG: Arterial-ventricular coupling with aging and disease. Front Physiol 2012, 3:90.

30. Desai AS, Mitchell GF, Fang JC, Creager MA: Central aortic stiffness is increased in patients with heart failure and preserved ejection fraction. J Card Fail 2009, 15:658-664.

31. Borlaug BA, Olson TP, Lam CS, Flood KS, Lerman A, Johnson BD, Redfield MM: Global cardiovascular reserve dysfunction in heart failure with preserved ejection fraction. J Am Coll Cardiol 2010, 56:845-854.

32. Fernandes VR, Polak JF, Edvardsen T, Carvalho B, Gomes A, Bluemke DA, Nasir K, O'Leary DH, Lima JA: Subclinical atherosclerosis and incipient regional myocardial dysfunction in asymptomatic individuals: the Multi-Ethnic Study of Atherosclerosis (MESA). J Am Coll Cardiol 2006, 47:2420-2428

33. Parrinello G, Colomba D, Bologna P, Licata A, Pinto A, Paterna S, Scaglione R, Licata G: Early carotid artery stenosis and cardiac diastolic abnormalities in hypertensive subjects. J Hum Hypertens 2004, 18:201-205.

34. Sega R, Corrao G, Bombelli M, Beltrame L, Facchetti R, Grassi G, Ferrario M, Mancia G: Blood pressure variability and organ damage in a general population: results from the PAMELA study (Pressioni Arteriose Monitorate E Loro Associazioni). Hypertension 2002, 39:710-714.

35. Aeschbacher BC, Hutter D, Fuhrer J, Weidmann P, Delacrétaz E, Allemann Y: Diastolic dysfunction precedes myocardial hypertrophy in the development of hypertension. Am J Hypertens 2001, 14:106-113.

36. Redfield MM, Jacobsen SJ, Borlaug BA, Rodeheffer RJ, Kass DA: Age- and gender-related ventricular-vascular stiffening: a community-based study. Circulation 2005, 112:2254-2262.

37. Levitan EB, Kaciroti N, Oparil S, Julius S, Muntner P: Blood pressure measurement device, number and timing of visits, and intra-individual visit-to-visit variability of blood pressure. J Clin Hypertens (Greenwich) 2012, $14: 744-750$

doi:10.1186/1471-2261-14-188

Cite this article as: Okada et al:: Visit-to-visit blood pressure variability is a marker of cardiac diastolic function and carotid atherosclerosis. BMC Cardiovascular Disorders 2014 14:188.

\section{Submit your next manuscript to BioMed Central and take full advantage of:}

- Convenient online submission

- Thorough peer review

- No space constraints or color figure charges

- Immediate publication on acceptance

- Inclusion in PubMed, CAS, Scopus and Google Scholar

- Research which is freely available for redistribution 